\title{
Vacuoles Play a Decisive Role in Calcium Homeostasis in Neurospora crassa
}

\author{
By GERD CORNELIUS† AND HIDEAKI NAKASHIMA* \\ National Institute for Basic Biology, Myodaijicho, Okazaki 444, Japan
}

(Received 2 February 1987; revised 11 April 1987)

\begin{abstract}
Mutants of the filamentous fungus Neurospora crassa which grow well only in a medium in which the concentration of calcium is lower than in the medium used for culture of the wild-type strain were isolated by use of the ionophore A23187 and medium which contained a high concentration of calcium. These mutants showed a significantly lower uptake of calcium into their vacuoles than the wild-type, while other activities associated with the transport of calcium across several other types of membrane were not affected. The results indicated an essential role for the vacuoles in the regulation of the cytosolic concentration of calcium.
\end{abstract}

\section{INTRODUCTION}

In addition to its well-known participation in muscle contraction, calcium plays a crucial role in a variety of other cellular processes, such as secretion, intracellular transport and movement, and the communication of signals (Marme, 1985; Rasmussen et al., 1984). Whereas the cytosolic concentration of calcium in a non-activated cell is in the range $10^{-8}-10^{-6} \mathrm{M}$, the extracellular concentration typically exceeds this value by several orders of magnitude (Bygrave, 1978; Rasmussen et al., 1984; Williamson \& Ashley, 1982). Because calcium in high concentrations is toxic to the cell, an effective system for the regulation of the intracellular concentration of calcium is required. This system consists of a number of calcium pumps which are located in the plasma membrane as well as in the membranes of various intracellular organelles, such as the mitochondria and the endoplasmic reticulum. These organelles serve as compartments for the storage of calcium, and are able to take up and release calcium ions. With respect to the mechanism of calcium transport, two general systems can be distinguished. One kind of pump uses the energy derived directly from the hydrolysis of ATP, while the other involves an antiporter which exchanges calcium for another ion, for example $\mathrm{H}^{+}$or $\mathrm{Na}^{+}$. The transport of calcium across the plasma membrane of Neurospora crassa has been shown to be linked to an electrogenic ATPase by an $\mathrm{H}^{+} / \mathrm{Ca}^{2+}$ antiporter (Stroobant \& Scarborough, 1979). However, it remained to be determined whether or not this pump is the only system used to maintain the calcium content of $N$. crassa at a constant, low level. In order to establish the nature of the decisive transport system, we undertook the isolation of mutants with phenotypic differences in the metabolism of calcium.

Calcium is important for the function of the circadian clock which regulates the conidiation rhythm in $N$. crassa (Nakashima, 1984). Isolation of mutants with phenotypic differences in the metabolism of calcium should contribute to an increased understanding of the relationship between clock function and the metabolism of calcium. We thus used the band $(b d)$ strain of $N$. crassa for isolation of mutants, and succeeded in isolating two whose growth is optimum at lower concentrations of calcium than are present in the medium which supports growth of the wild-

† Present address: Institut für Genetik, Universität des Saarlandes, D6600 Saarbrücken, FRG.

Abbreviation: DCCD, $N, N^{\prime}$-dicyclodihexylcarbodiimide. 
type. We then compared the transport of calcium in various other organelles from these mutants with the corresponding activities in the wild-type.

\section{METHODS}

Culture conditions. Stock cultures were maintained in Horowitz complete medium (Horowitz, 1947), under continuous light at $25^{\circ} \mathrm{C}$. Conidia were inoculated into Vogel's medium (Vogel, 1956) which contained sucrose as indicated in the descriptions of individual experiments.

Mutagenesis and mycelial growth. The wild-type band $(b d)$ strain was used in all experiments. Two mutants, ca- 19 and ca-31, which also had the $b d$ mutation, were isolated by the method described by Davis $\&$ De Serres (1970), with slight modifications. Conidia of the $b d$ strain of $N$. crassa were exposed to UV light for $4 \mathrm{~min}$, and then cultured in Vogel's medium containing $2 \%$ sucrose, $1 \mu \mathrm{M}$ - $\mathrm{A} 23187$ and $5 \mathrm{mM}-\mathrm{CaCl}_{2}$. At various times, growing hyphae were removed by filtration through glasswool. After $3 \mathrm{~d}$, conidia that had not germinated were washed once with distilled water and inoculated into sorbose complete medium (Malling, 1966) and cultured for $2 \mathrm{~d}$ at $26^{\circ} \mathrm{C}$ in the dark. Individual colonies were then transferred to Horowitz complete medium and the effects of external calcium concentration on mycelial growth were determined.

For determination of growth rate, conidia $\left(2 \times 10^{6}\right)$ were inoculated into $20 \mathrm{ml}$ of culture medium which contained Vogel's salts and $2 \%$ sucrose. After removal of the culture medium by paper filtration under suction, mycelia, still on the filter paper, were treated with $5 \mathrm{ml}$ cold $10 \%(\mathrm{w} / \mathrm{v}) \mathrm{TCA}$. They were put into $5 \mathrm{ml} 0.5 \mathrm{M}-\mathrm{NaOH}$ and incubated at $90{ }^{\circ} \mathrm{C}$ for $30 \mathrm{~min}$. Samples of the extracts were used for assays of protein concentration.

Isolation of organelles. For growth of the $b d$ wild-type strain Vogel's medium containing $2 \%$ sucrose and $1 \mathrm{~mm}$ $\mathrm{CaCl}_{2}$ was inoculated with $5.7 \times 10^{9}$ conidia $\mathrm{I}^{-1}$.

For growth of the mutants ca-19 and ca-31 Vogel's medium containing $2 \%$ sucrose and $10 \mu \mathrm{M}-\mathrm{CaCl}_{2}$ was inoculated with $5.7 \times 10^{9}$ and $11.4 \times 10^{9}$ conidia $1^{-1}$, respectively. After growing for $23 \mathrm{~h}$ in continuous light at $25^{\circ} \mathrm{C}$ on a reciprocal shaker, the mycelia were harvested by filtration through cheesecloth. The organelles were isolated essentially by a combination of the methods of Cramer et al. (1983) for mitochondria and vacuoles and of Borgeson \& Bowman (1983) for plasma membrane vesicles and microsomes. Buffer (10 mM-HEPES/NaOH, $\mathrm{pH}$ 7.45) containing $1 \mathrm{M}$-sorbitol, $1 \mathrm{mM}-\mathrm{Na}_{2} \mathrm{ATP}$ and $1 \mathrm{~mm}$-phenylmethylsulphonyl fluoride was used throughout the homogenization and washing procedures. Briefly, cells were disrupted by means of a bead-beater (Biospec, Bartlesville, Okla., USA). The glass beads were removed by filtration of the homogenate. The filtrate was centrifuged at $1000 \mathrm{~g}$ and the resulting supernatant filtered again through a Whatman 934-AH filter. This filtrate was centrifuged for $30 \mathrm{~min}$ at $14000 \mathrm{~g}$. Organelles were isolated by two different centrifugation steps: the $14000 \mathrm{~g}$ pellet was layered onto a discontinuous sucrose gradient $(1.2 \mathrm{M}$ and $1.6 \mathrm{M}$-sucrose buffered at $\mathrm{pH} 7.4)$ and centrifuged for $2 \mathrm{~h}$ at $43000 \mathrm{~g}$ to separate mitochondria and vacuoles; the $14000 \mathrm{~g}$ supernatant was layered onto a continuous sucrose density gradient (14-42\% sucrose, w/w, buffered at $\mathrm{pH} 7 \cdot 4$ ) and centrifuged for $2 \mathrm{~h}$ at $94000 \mathrm{~g}$ to separate plasma membranes and endoplasmic reticulum. Immediately thereafter the fractions were analysed for protein content (Bradford, 1976) and assayed for calcium transport activity.

Determination of calcium uptake by isolated cell fractions. This was measured using $20 \mu \mathrm{g}$ vacuoles, $25 \mu \mathrm{g}$ plasma membrane vesicles, $50 \mu \mathrm{g}$ mitochondria or $50 \mu \mathrm{g}$ microsomes (as determined by the protein content of each fraction). A $100 \mu$ assay mixture (pH 7.4) was incubated with $7.4 \mathrm{kBq}{ }^{45} \mathrm{Ca}$ for $2 \mathrm{~min}$ (vacuoles) or $5 \mathrm{~min}$ (other fractions) at $25^{\circ} \mathrm{C}$. The assay mixtures contained the following: for the vacuolar fractions, $10 \mathrm{~mm}-\mathrm{MgSO}_{4}, 5 \mathrm{~mm}-$ $\mathrm{NaN}_{3}, 1 \mathrm{~mm}-\mathrm{Na}_{3} \mathrm{VO}_{4}, 10 \mathrm{mM}-\mathrm{ATP}, 0.4 \mathrm{mM}-\mathrm{CaCl}_{2}$; for the mitochondrial fraction, $10 \mathrm{mM}-\mathrm{MgSO}_{4}, 5 \mathrm{~mm}-$ $\mathrm{K}_{2} \mathrm{HPO}_{4}, 1 \mathrm{mM}-\mathrm{Na}_{3} \mathrm{VO}_{4}, 100 \mathrm{mM}-\mathrm{KNO}_{3}, 10 \mathrm{mM}-\mathrm{ATP}, 0.1 \mathrm{mM}-\mathrm{CaCl}_{2}$; for the plasma membrane vesicles, $10 \mathrm{~mm}-$ $\mathrm{MgSO}_{4}, 10 \mathrm{~mm}-\mathrm{NaSCN}, 5 \mathrm{~mm}-\mathrm{NaN}_{3}, 100 \mathrm{mM}-\mathrm{KNO}_{3}, 10 \mathrm{mM}-\mathrm{ATP}, 0.1 \mathrm{~mm}-\mathrm{CaCl}_{2}$; and for the microsomes, $10 \mathrm{mM}-\mathrm{MgSO}_{4}, 5 \mathrm{mM}-\mathrm{NaN}_{3}, 100 \mathrm{mM}-\mathrm{KNO}_{3}, 10 \mathrm{mM}-\mathrm{ATP}, 0.1 \mathrm{mM}-\mathrm{CaCl}_{2}$. Uptake was stopped by filtering the mixture through a Millipore AAWP filter and washing with $6 \mathrm{ml}$ ice-cold preparation buffer. Radioactivity was determined in a liquid scintillation counter. As observed in preliminary experiments, calcium transport was ATPdependent but was reduced by only $60 \%$ when ATP was omitted from the test mixture, which may be due to residual ATP in the preparation buffer. For this reason zero-time controls were used as blanks.

Other methods. The concentration of calcium in the various fractions was determined by atomic absorption spectroscopy. Arginine content was measured by the method of Van Pilsum et al. (1956) and vacuolar $\mathrm{H}^{+}-\mathrm{ATPase}$ activity by the method of Bowman (1983).

Chemicals. Nucleotides and enzymes were purchased from Sigma, ${ }^{45} \mathrm{CaCl}_{2}$ from Amersham and A23187 from Calbiochem.

\section{RESULTS}

\section{Isolation of mutants and mycelial growth}

Mutants that could grow only in a medium which contained a low concentration of calcium were isolated from conidia that did not grow in the culture medium which contained a high 


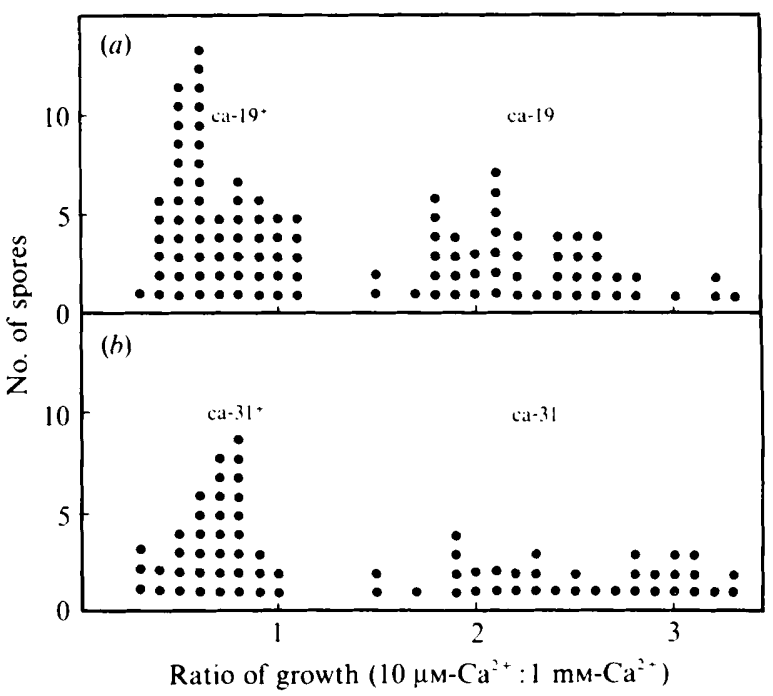

Fig. 1. Distribution of ratios of growth rates among progeny of a cross between ca-19 and ca-19+ $(a)$ and between ca-31 and ca-31+ $(b)$. Mutant strains were backcrossed with the $b d$ strain and progeny were isolated. Samples of conidia suspended in distilled water were inoculated into medium that contained Vogel's salts without calcium, $2 \%(\mathrm{w} / \mathrm{v})$ sucrose, and $10 \mu \mathrm{M}$ or $1 \mathrm{mM}-\mathrm{CaCl}_{2}$ and were cultured for $1 \mathrm{~d}$ with shaking. Mycelia were collected on filter paper and the dry wt was measured.

concentration of calcium and the ionophore A23187. Two mutants, ca-19 and ca-31, were isolated from a total of several thousand colonies. The mutations segregated as single nuclear genes when they were backcrossed to the wild-type $b d$ strain. Fig. 1 illustrates the $1: 1$ segregation among random spores. The fluctuations in the ratio of growth of mutant strains were due to the very poor growth in the culture medium which contained $1 \mathrm{~mm}$-calcium.

Mycelial growth of the mutant strains ca- 19 and ca-31, as compared to the $b d$ wild-type strain, was greatest when the calcium concentration in the medium was low (Fig. 2). The optimum calcium concentration for the mutants was about $10 \mu \mathrm{M}$, whereas growth of the wild-type was optimum at a 100-fold higher concentration. At optimum calcium concentrations, the growth rates of the mutant strains in the exponential phase were almost equal to that of $b d$ wild-type strain (Fig. 3).

\section{Uptake of calcium by fractionated cellular organelles}

Calcium uptake by vacuoles was far greater than that by the other organelles (Table 1). In the mutant strains ca-19 and ca-31, calcium uptake by vacuoles was much lower than in the $b d$ wildtype strain. This difference is the only statistically significant difference between the wild-type and the mutants ( $1 \%$ level, Student's $t$-test). The other systems involved in calcium transport did not seem to play as prominent a role (quantitatively) and were not altered in the mutants. The transport of calcium into vacuoles from the wild-type did not change significantly when the wild-type was cultured in medium with only $10 \mu \mathrm{M}-\mathrm{CaCl}_{2}$ (as used for the growth of the mutants), so that induction of the transport systems by high concentrations of calcium can be ruled out.

\section{Other features of vacuoles of the wild-type strain}

Properties other than calcium uptake were also altered in isolated vacuoles of the mutants ca-19 and ca-31 as compared to the wild-type. The calcium and arginine contents of the vacuolar fraction, as well as the activity of the vacuolar $\mathrm{H}^{+}$-ATPase, were decreased in the mutants (Table 2). Fig. 4 shows that calcium uptake by vacuoles required magnesium ions: that part of 


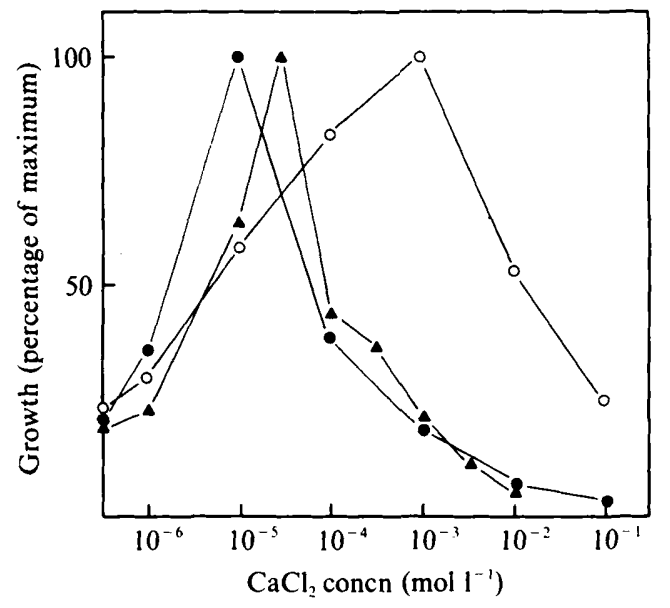

Fig. 2

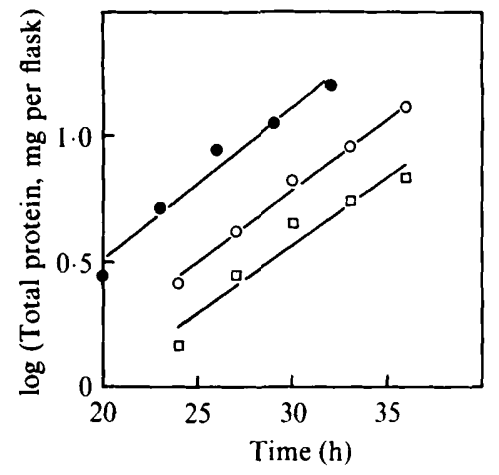

Fig. 3

Fig. 2. Dependence of mycelial growth of different strains on the external concentration of calcium. Conidia $\left(2 \times 10^{6}\right)$ were inoculated into $20 \mathrm{ml}$ culture medium with different concentrations of $\mathrm{CaCl}_{2}$ and cultured for the time required for the fastest growing culture in a given series to achieve a cell mass of about $5 \mathrm{mg}$ protein per flask. This time was about $24 \mathrm{~h}$ for the wild-type $(O), 30 \mathrm{~h}$ for ca-19 (O) and $36 \mathrm{~h}$ for ca-31 (A).

Fig. 3. Mycelial growth rate at the optimum concentration of calcium for different strains. The procedures were the same as described in the legend to Fig. 1. Mycelia were harvested at different times as indicated on the abscissa. The concentration of calcium in the culture medium for each strain was $1 \mathrm{mM}$ for the $b d$ wild-type (O) and $10 \mu \mathrm{M}$ for the mutants ca-19 (O) and ca-31 ( $\square$ ).

Table 1. Calcium uptake by isolated organelles

Values are means of $n$ experiments $\pm \mathrm{SE}$.

\begin{tabular}{|c|c|c|c|}
\hline Organelle & Mutant & $n$ & $\begin{array}{c}\text { Calcium uptake } \\
{\left[\text { nmol } \min ^{-1}(\text { mg protein })^{-1}\right.}\end{array}$ \\
\hline Vacuoles & $\begin{array}{c}b d \\
\text { ca-19 } \\
\text { ca-31 }\end{array}$ & $\begin{array}{r}13 \\
9 \\
6\end{array}$ & $\begin{array}{c}112.0 \pm 23.0 \\
21.0 \pm 5.6 \\
17.0 \pm 3.6\end{array}$ \\
\hline Mitochondria & $\begin{array}{c}b d \\
\text { ca-19 } \\
\text { ca-31 }\end{array}$ & $\begin{array}{r}13 \\
9 \\
6\end{array}$ & $\begin{array}{l}2.1 \pm 0.3 \\
1.9 \pm 0.3 \\
1.8 \pm 0.2\end{array}$ \\
\hline Plasma membrane vesicles & $\begin{array}{c}b d \\
\text { ca-19 } \\
\text { ca-31 }\end{array}$ & $\begin{array}{r}15 \\
9 \\
6\end{array}$ & $\begin{array}{l}5.6 \pm 1.1 \\
5.6 \pm 0.9 \\
6.4 \pm 1.0\end{array}$ \\
\hline Microsomes & $\begin{array}{c}b d \\
\text { ca-19 } \\
\text { ca-31 }\end{array}$ & $\begin{array}{r}13 \\
9 \\
6\end{array}$ & $\begin{array}{l}3.4 \pm 0.8 \\
2.9 \pm 0.5 \\
2.9 \pm 0.3\end{array}$ \\
\hline
\end{tabular}

transport apparently independent of $\mathrm{Mg}^{2+}$ (about $25 \%$ of the control) may be due to residual magnesium ions present in the vacuolar fraction as supposed by Zerez et al. (1986) for vacuolar arginine transport. Azide and vanadate reduced calcium uptake only slightly but the effect of the proton transport inhibitors (Bowman \& Bowman, 1982; Solioz, 1984) $N, N^{\prime}$-dicyclohexylcarbodiimide (DCCD), $\mathrm{NO}_{3}^{-}$and $\mathrm{SCN}^{-}$was much greater (Fig. 4). 


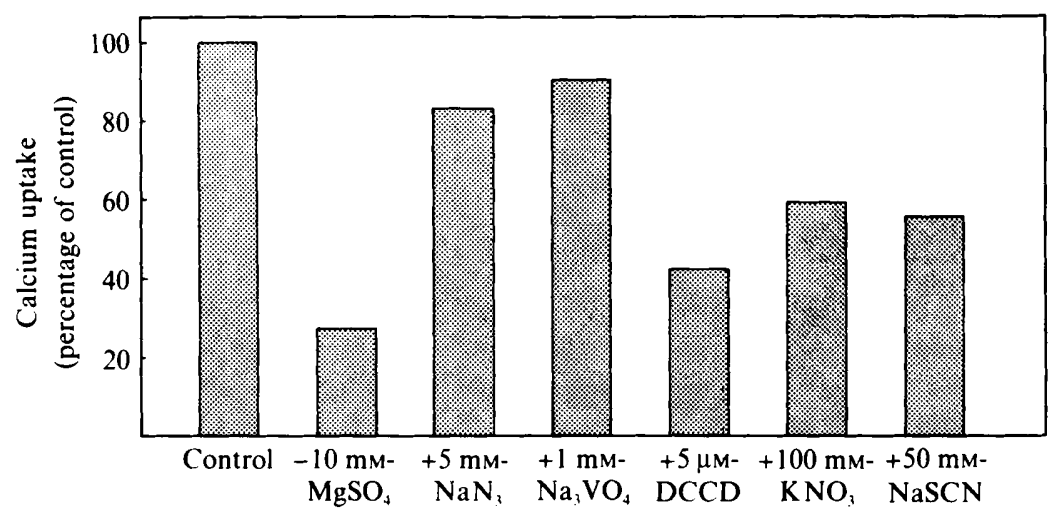

Fig. 4. Effects of different compounds on the uptake of calcium by vacuoles of the wild-type $b d$ strain. The control value of calcium uptake was taken as $100 \% . \mathrm{MgSO}_{4}$ was included in all reaction mixtures except when its own effect was determined. DCCD was added $\mathrm{I} \mathrm{h}$ before the start of the incubation and its effect was measured in the presence of azide and vanadate.

Table 2. Comparison of the vacuolar fractions of $N$. crassa ca-19 and ca-31 with the wild-type

Calcium and arginine contents and ATPase activity were determined in isolated vacuolar fractions of the $b d$ wild-type and the mutants, and were compared to calcium transport (cf. Table 1). The values for the $b d$ wild-type were each set to 100 ; these absolute values were $112 \mathrm{nmol} \mathrm{min}^{-1}$ (mg protein) $^{-1}$ (calcium uptake), $4.12 \mathrm{mg}$ (g protein) ${ }^{-1}$ (calcium content), $2.94 \mathrm{nmol}$ (g protein)-1 (arginine content) and $0 \cdot 11 \mu \mathrm{mol} \mathrm{P}_{\mathrm{i}} \min ^{-1}$ (mg protein) $)^{-1}$ (ATPase activity).

$\begin{array}{lcccc}\text { Strain } & \begin{array}{c}\text { Calcium } \\ \text { transport }\end{array} & \begin{array}{c}\text { Calcium } \\ \text { content }\end{array} & \begin{array}{c}\text { Arginine } \\ \text { content }\end{array} & \begin{array}{c}\text { ATPase } \\ \text { activity }\end{array} \\ \text { bd } \text { wild-type } & 100 & 100 & 100 & 100 \\ \text { ca-19 } & 19 & 10 & 32 & 39 \\ \text { ca-31 } & 15 & 6 & 23 & 50\end{array}$

\section{DISCUSSION}

Our results show that in $N$. crassa, vacuoles isolated from the wild-type $b d$ strain have a much greater ability to transport calcium ions than vacuoles isolated from mutants which can only grow at low calcium concentrations. This difference indicates that, in $N$. crassa, the vacuolar uptake of calcium is responsible for sequestering excess and hazardous amounts of free calcium from the cytosol. Therefore, mutants with a reduced ability to store calcium in the vacuole will suffer from a toxic excess of cytosolic calcium when grown in a medium which contains a high concentration of calcium.

Cytosolic calcium in animal cells is maintained at constant levels by the action of various pumps in the plasma membrane, in the mitochondrial membranes and in the endoplasmic reticulum (Bygrave, 1978; Carafoli \& Crompton, 1978). Higher plants also have calcium pumps located in the membranes of various organelles (Buckhout, 1983; Dieter \& Marme, 1980; Hager \& Hermsdorf, 1981; Kreimer et al., 1985; Rasi-Caldogno et al., 1982; Schumaker \& Sze, 1985). Recently, vacuolar systems for the transport of calcium have been detected in oat (Schumaker \& Sze, 1985), carrot (Bush \& Sze, 1986) and red beet (Blumwald \& Poole, 1986). Yeast vacuoles also contain calcium transport systems (Ohsumi \& Anraku, 1983; Eilam et al., 1985; Okorokov et al., 1985). Vacuoles are organelles that are possibly analogous to the lysosomes of animal cells in that they are the site of intracellular digestion; they also contain significant amounts of metabolites such as arginine and other basic amino acids. Arginine is transported into yeast vacuoles by an $\mathrm{H}^{+}$/amino acid antiporter, the energy being applied by $\mathrm{H}^{+}$-ATPase-dependent ATP hydrolysis (Ohsumi \& Anraku, 1983). Vacuoles in $N$. crassa are also used as storage compartments for 
arginine (Vaughn \& Davis, 1981), and we showed that vacuoles in the wild-type bd strain contain an increased amount of arginine compared to vacuoles of mutants with reduced ability to transport calcium. In yeast, the uptake of calcium by vacuoles is coupled to the $\mathrm{H}^{+}$-ATPase in the same way as is arginine uptake (Ohsumi \& Anraku, 1983). The vacuolar $\mathrm{H}^{+}$-ATPase of $N$. Crassa has recently been partially purified (Bowman et al., 1986). Because the effects of various compounds on the uptake of calcium by vacuoles of $N$. crassa (Fig. 4) are characteristic of a vacuolar $\mathrm{H}^{+}$-ATPase, it is possible that, in $N$. crassa the vacuolar transport of calcium is also coupled to a proton-translocating ATPase. This is supported by the recent observation of Zerez et al. (1986) that arginine uptake by vacuolar membrane vesicles of $N$. crassa also seems to depend on vacuolar $\mathrm{H}^{+}$-ATPase activity.

We thank Dr T. Kondo (Okazaki) for the help in determining concentrations of calcium by atomic absorption spectroscopy, and Dr J. W. Hastings (Cambridge, Mass.) for critical reading of the manuscript. G. C. was recipient of a grant from the Japanese Society for the Promotion of Science.

\section{REFERENCES}

Blumwald, E. \& Poole, R. J. (1986). Kinetics of $\mathrm{Ca}^{2+} / \mathrm{H}^{+}$antiport in isolated tonoplast vesicles from storage tissue of Beta vulgaris L. Plant Physiology $\mathbf{8 0 ,}$ 727-731.

Borgeson, C. E. \& Bowman, B. J. (1983). Isolation and characterization of the Neurospora crassa endoplasmic reticulum. Journal of Bacteriology 156, 362368.

Bowman, E. J. (1983). Comparison of the vacuolar membrane ATPase of Neurospora crassa with the mitochondrial and plasma membrane ATPases. Journal of Biological Chemistry 258, 15238-15244.

Bowman, E. J. \& Bowman, B. J. (1982). Identification and properties of an ATPase in vacuolar membranes of Neurospora crassa. Journal of Bacteriology 151, 1326-1337.

Bowman, E. J., Mandala, S., Taiz, L. \& Bowman, B. J. (1986). Structural studies of the vacuolar membrane ATPase from Neurospora crassa and comparison with the tonoplast membrane ATPase from Zea mays. Proceedings of the National Academy of Sciences of the United States of America 83, 48-52.

BRADFORD, M. M. (1976). A rapid and sensitive method for the quantitation of microgram quantities of protein utilizing the principle of dye-binding. Analytical Biochemistry 72, 248-254.

Buckhout, T. J. (1983). ATP-dependent Ca ${ }^{2+}$ transport in endoplasmic reticulum isolated from roots of Lepidium sativum L. Planta 159, 84-90.

Bush, D. R. \& SzE, H. (1986). Calcium transport in tonoplast and endoplasmic reticulum vesicles isolated from cultured carrot cells. Plant Physiology 80, 549-555.

Bygrave, F. L. (1978). Calcium movements in cells. Trends in Biochemical Sciences 3, 175-178.

Carafoli, E. \& CROMPTON, M. (1978). The regulation of intracellular calcium. Current Topics in Membrane Transport 10, 151-216.

Cramer, C. L., Ristow, J. L., Paulus, T. J.\& Davis, R. H. (1983). Methods for mycelial breakage and isolation of mitochondria and vacuoles of Neurospora. Analytical Biochemistry 128, 384-392.

Davis, R. H. \& DE SerRes, F. J. (1970). Genetic and microbiological research techniques for Neurospora crassa. Methods in Enzymology 17A, 79-143.
Dieter, P. \& MARMe, D. (1980). $\mathrm{Ca}^{2+}$ transport in mitochondrial and microsomal fractions from higher plants. Planta 150, 1-8.

Eilam, Y., Lavi, H. \& Grossowicz, N. (1985). Cytoplasmic $\mathrm{Ca}^{2+}$ homeostasis maintained by a vacuolar $\mathrm{Ca}^{2+}$ transporting system in the yeast Saccharomyces cerevisiae. Journal of General Microbiology 131, 623-629.

HAGER, A. \& HeRmsdorf, P. (1981). A H $\mathrm{H}^{+} / \mathrm{Ca}^{2+}$ antiporter in membranes of microsomal vesicles from maize coleoptiles, a secondary energized $\mathrm{Ca}^{2+}$ pump. Zeitschrift für Naturforschung 36c, 1009-1012.

Horowitz, N. H. (1947). Methionine synthesis in Neurospora. The isolation of cystathionine. Journal of Biological Chemistry 171, 255-264.

Kreimer, G., Melkonian, M., Holtum, A. M. \& LATZKO, E. (1985). Characterization of calcium fluxes across the envelope of intact spinach chloroplasts. Planta 166, 515-523.

Malling, H. V. (1966). Methods for the identification of genetic alterations by specific revertibility tests in Neurospora crassa. Neurospora Newsletter 9, 13-14.

MARMe, D. (1985). Calcium. Molekulare Mechanismen der zellularen Funktion. Naturwissenschaften 72, 113-117.

NaKashima, H. (1984). Calcium inhibits phase shifting by the calcium ionophore A23187 of the circadian conidiation rhythm of Neurospora crassa. Plant Physiology 74, 268-271.

OHSUMI, Y. \& ANRAKU, Y. (1983). Calcium transport driven by a proton motive force in vacuolar membrane vesicles of Saccharomyces cerevisiae. Journal of Biological Chemistry 258, 5614-5617.

OKorokov, L. A., Kulakovskaya, T. V., LichKo, L. P. \& Polorotova, E. V. (1985). $\mathrm{H}^{+} /$ion antiport as the principle mechanism of transport systems in the vacuolar membrane of the yeast Saccharomyces carlsbergensis. FEBS Letters 192, 303-306.

Rasi-Caldogno, F., de Michelis, M. I. \& PugliarELLO, M. C. (1982). Active transport of $\mathrm{Ca}^{2+}$ in membrane vesicles from pea. Evidence for a $\mathrm{H}^{+} / \mathrm{Ca}^{2+}$ antiport. Biochimica et biophysica acta 693 , 287-295.

Rasmussen, H., Kojima, I., Kojima, K., Zawalich, W. \& APFELDORF, W. (1984). Calcium as intra- 
cellular messenger : sensitivity modulation, C-kinase pathway, and sustained cellular response. Advance Cyclic Nucleotide Protein Phosphorylation Research 18, 159-193.

Schumaker, K. S. \& SZE, H. (1985). A Ca ${ }^{2+} / \mathrm{H}^{+}$ antiport system driven by the proton electrochemical gradient of a tonoplast $\mathrm{H}^{+}-\mathrm{A}$ TPase from oat roots. Plant Physiology 79, 1111-1117.

Solioz, M. (1984). Dicyclohexylcarbodiimide as a probe for proton translocating enzymes. Trends in Biochemical Sciences 9, 309-312.

Stroobant, P. \& Scarborough, G. A. (1979). Active transport of calcium in Neurospora plasma membrane vesicles. Proceedings of the National Academy of Sciences of the United States of America 76, 31023106.

Van Pilsum, J. F., Martin, R. P., Kito, E. \& Hess, J.
(1956). Determination of creatine, creatinine, arginine, guanidinoacetic acid, guanidine, and methylguanidine in biological fluids. Journal of Biological Chemistry' 222, 225-236.

Vaughn, L. E. \& Davis, R. H. (1971). Purification of vacuoles from Neurospora crassa. Molecular and Cellular Biology 1, 797-806.

Vogel, H. J. (1956). A convenient growth medium for Neurospora (medium N). Microbial Genetic Bulletin 13, 42-43.

Williamson, R. E. \& Ashley, C. C. (1982). Free Ca ${ }^{2+}$ and cytoplasmic streaming in the alga Chara. Nature, London 296, 647-651.

Zerez, C. R., Weiss, R. L., Franklin, C. \& Bowman, B. J. (1986). The properties of arginine transport in vacuolar membrane vesicles of Neurospora crassa. Journal of Biological Chemistry 261, 8877-8882. 